\title{
Límites a la Universalidad de los Derechos \\ Humanos: Representaciones Sociales en el \\ Sistema Judicial sobre los Migrantes \\ Internacionales como Titulares de Derechos
}

\author{
Anahí González \\ Universidad de Buenos Aires (BA), Argentina. E-mail: anahipgonzalez@gmail.com
}

\section{INTRODUCCIÓN}

T as migraciones forman parte de la historia de la humanidad. Con

L los procesos de construcción de los Estados Nacionales, las migraciones, así como los sujetos movilizados, adquirieron un carácter particular, involucrando cuestiones tales como la edificación de las fronteras nacionales, la definición de ciudadanía y de identidad nacional. Paulatinamente, los procesos de globalización e internacionalización económica, comunicacional, política y de transporte intensificaron los contactos a nivel mundial haciendo que lo global pareciera más pequeño, más cercano, más local. No obstante, estos cambios supusieron también procesos de desigualdad y exclusión que aquellos migrantes, que se trasladaban y trasladan en búsqueda de mejores condiciones de vida, se ven compelidos a atravesar cotidianamente.

De la misma manera, las diversas disciplinas sociales, que tomaron y toman como objeto de estudio a las migraciones, se plantearon renovados interrogantes y desarrollaron perspectivas teóricas y metodológicas en función de los cambios que los procesos migratorios han manifestado, sean estos aspectos demográficos, políticos, socioculturales o económicos.

A diferencia de las teorías clásicas sobre las migraciones internacionales, las teorizaciones más recientes intentan progresivamente explicar DADOS - Revista de Ciências Sociais, Rio de Janeiro, vol. 60, no 1, 2017, pp. 45 a 78. 
las migraciones a partir de sus espacios trasnacionales. Mientras la primera perspectiva conceptualiza la migración como un cambio duradero de país de residencia, la segunda analiza la migración internacional de personas y grupos, ya no como un evento excepcional y episódico en el curso de vida, sino como una forma de vida cotidiana. Como consecuencia, se pregunta acerca de qué es lo que le da continuidad al proceso migratorio y qué nuevos espacios trasnacionales están surgiendo con la migración internacional reciente. Ejemplos de dichos enfoques son los de Basch et al. (1995), Portes (2001), Suarez Navas (2008), entre otros. En el marco de estos debates, autores como Sassen (2007) se refieren a la necesidad de pensar nuevas estrategias teórico-metodológicas para el estudio de las migraciones en épocas de globalización, ya que fenómenos como la exportación de mano de obra, por ejemplo, instauran lazos tangencialmente diferentes, entre los países de origen y los países receptores, a los que se establecían en las épocas del colonialismo.

En el campo de la sociología, las migraciones han estado presentes como objeto de estudio desde sus comienzos. El proprio surgimiento y desarrollo de la sociología está muy vinculado a los movimientos poblacionales, tal como lo reflejaron autores clásicos de la disciplina. Por su parte, en Argentina, las oleadas migratorias, especialmente italiana y española, de fines del siglo XIX y principios del XX, han sido estudiadas en profundidad, relegándose del campo de investigación el análisis de las migraciones regionales, también presentes en la misma época. El enfoque prevaleciente en estos abordajes ha sido el de los estudios historiográficos y demográficos. De la misma manera, los trabajos de Gino Germani $(1964 ; 2010)$ han sido el puntapié inicial de una tradición investigativa del campo migratorio que llega hasta nuestros días.

Paulatinamente, y acompañando también los cambios de los mismos procesos migratorios, los estudios sobre las oleadas migratorias provenientes de Europa, fueron dejando su lugar a otros que centraron su atención en las migraciones regionales (provenientes de Bolivia, Paraguay, Chile, Perú, Brasil) fundamentalmente respecto a las dimensiones laborales. De la misma manera, tanto localmente como en otros países se comienza a trabajar a partir del análisis de las redes y cadenas migratorias (Pedone, 2010). Del mismo modo, los discursos políticos de los gobernantes, de los medios de comunicación, las políticas migratorias y el marco legal se han constituido en nuevas dimensiones 
abordadas (Oteiza, Novick y Aruj, 1996; Oteiza y Novick, 2000; Mármora, 2004; Novick, 2008).

Siguiendo las aperturas del debate migratorio contemporáneo, este artículo pretende profundizar sobre el aspecto de construcción de la otredad migrante y sus implicaciones en la universalidad de los derechos humanos. Se consideran centrales las tramas discursivas que se elaboran en la sociedad receptora así como los procesos que refuerzan el imaginario social acerca del grado de legitimidad del acceso a derechos que los migrantes pueden o no tener. El migrante, en tanto sujeto que vive en una sociedad organizada por un Estado nacional diferente al de origen se presenta como un ejemplo paradigmático para someter a prueba el discurso de universalización de los derechos humanos.

El objetivo general del artículo es analizar las representaciones sociales existentes en el sistema judicial del Área Metropolitana de Buenos Aires (Argentina) acerca de los migrantes internacionales llegados desde mediados del siglo XX hasta hoy, en su dimensión vinculada a los derechos humanos. Para ello, se analizan los resultados de una serie de entrevistas en profundidad ${ }^{1}$ realizadas a miembros del sistema judicial. Para las mismas, se confeccionó un instrumento de registro (guía de pautas) que fue empleado en la totalidad de los casos entrevistados (cincuenta). Para su procesamiento y análisis se incorporaron las desgravaciones textuales de los discursos a una unidad hermenéutica del programa Atlas Ti. Aquí se presentan los resultados de ese análisis a partir de las siguientes dimensiones que nos permiten acercarnos a las percepciones que los miembros del sistema judicial tienen en relación a los extranjeros como sujetos de derechos: política migratoria anhelada, competencia entre nativos y migrantes en el acceso a derechos económicos y sociales y concepción de ciudadanía restringida.

El artículo se estructura en tres partes. En primer lugar, se realizan algunas especificaciones acerca del abordaje teórico-metodológico. Para ello, se define el concepto de representación social y su importancia en relación a la investigación realizada. Después, se describe la unidad de análisis y de recolección de información y su contextualización con las modificaciones que a nivel normativo se han producido en Argentina a partir de la sanción de una nueva Ley Migratoria en el año 2003. En segundo lugar, se describen los resultados principales a partir de los tres ejes o dimensiones mencionados anteriormente. Finalmente, se discuten dichos resultados, presentándose a continuación las conclusiones del trabajo. 


\section{BASES TEÓRICO-METODOLÓGICAS}

\section{La Categoría de Representaciones Sociales}

La estrategia elegida para la aproximación al problema de investigación ha sido de carácter cualitativo. Esta decisión se basó en el objetivo general perseguido: conocer cuáles son las representaciones sociales, las ideas, percepciones e imaginarios de los entrevistados. Dadas las dificultades que la temática en cuestión implicaba, o sea, conocer las ideas acerca de los migrantes como sujetos de derechos, resultaba importante conocer el decir de los miembros de la institución judicial reduciendo, en el mayor grado posible, el discurso políticamente correcto o el sesgo de deseabilidad social (Cea D'Ancona, 2002, 2005)².

Con ese fin se hizo uso de la categoría de representaciones sociales. La misma tiene su nacimiento en el marco de la sociología. Autores clásicos, como Durkheim, la vinculan con la generación de lazos sociales creados por los individuos como miembros de un colectivo profesional, familiar, religioso, estatal, etc. Puede decirse entonces que las representaciones sociales consisten en una visión de la realidad, consensuada por un grupo. El desarrollo del concepto continúa también en la psicología. Jodelet (1986), por ejemplo, enmarca la existencia de las representaciones en la necesidad que tenemos todos los sujetos de saber a qué atenernos ante las contingencias del mundo que nos rodea, “(...) ellas nos orientan en la manera de designar y definir conjuntamente los diferentes aspectos de nuestra realidad diaria, en la manera de interpretarlos, influir sobre ellos y, en caso contrario, tomar una posición ante ellos y defenderla". En línea similar a Jodelet, tanto Moscovici (1979) como Berger y Luckmann (1986) entienden las representaciones sociales como recetas para la acción. Frente a un acontecimiento los sujetos poseemos en nuestro acervo de conocimientos modos típicos de proceder. En este aspecto, las representaciones no involucran per se relaciones de dominación. Sin embargo, cuando las mismas suponen jerarquizaciones, prejuicios o se enmarcan en relaciones previas asimétricas entre los sujetos involucrados pueden incluir procesos de discriminación o exclusión. Asimismo, poseen un efecto de verdad producto de basarse en el conocimiento del sentido común, en lo que "todo el mundo sabe".

En el proceso complejo de construcción de las representaciones se elaboran además justificaciones y explicaciones acerca del por qué de las 
mismas que, por ser una estilización de una realidad que es imposible aprehender y catalogar en su totalidad, está repleta de contradicciones. No obstante ello, para ser efectivas, los sujetos que las edifican no deben ser conscientes del carácter inventivo de la representación como tampoco de sus aspectos contradictorios.

La perspectiva investigativa que se ha decidido tomar es estudiar las migraciones desde las representaciones de la sociedad receptora, considerando que ello permite problematizar la idea de que

(...) miembros [de una sociedad] digan "nosotros" de sí mismos y "ellos" de los otros es algo universal. Pero de quién digan "nosotros" y de quién digan "ellos" es algo que puede variar" y en esa variación se hace presente una de las singularidades de los objetos de estudio de las ciencias sociales, esto es: la construcción significativa, constante y cambiante del mundo social por parte del ser humano (Elías, 1982:154).

El estudio del fenómeno migratorio a partir de las representaciones sociales de los sujetos nativos (particularmente aquí de miembros del sistema judicial) permite hacer visible no solo los imaginarios que se tienen del "otro migrante" sino que además puede evidenciarse lo que elaboran representacionalmente de sí mismos, de sus "iguales" y de aquellos que no lo son. En suma, se trata de aprehender el proceso de construcción de la extranjeridad a partir de un enfoque que estudia las migraciones:

[...] en términos relativos o relacionales considerando su historia e incluyendo en su abordaje, el nuevo proceso que se gesta con la construcción de su extranjeridad al interior de la trama de relaciones sociales que lo contiene en la sociedad receptora. Este abordaje relacional del migrante externo, incluye al nativo como actor social que participa en el proceso de otorgar sentido a la presencia del migrante, sentido que no siempre es reconocido por este último, sentido que puede ubicarlo en condiciones desiguales respecto al nativo. Es un sentido que puede crear condiciones de tensión y hasta de conflictividad (Cohen, 2004:s/p).

En definitiva, la potencialidad de analizar las representaciones permite evidenciar cuáles son las imágenes que permanecen y se reactualizan en el imaginario social acerca de "nosotros" y de los "otros", en este caso, los migrantes. Asimismo, ese imaginario social, entendido 
como universos de significaciones que instituyen una sociedad, es inseparable de la cuestión del poder. En los términos de Baczko:

el ejercicio del poder (...) pasa por el imaginario colectivo. Ejercer un poder simbólico no significa agregar lo ilusorio a un poderío "real", sino multiplicar y reforzar una dominación efectiva por la apropiación de los símbolos, por la conjunción de las relaciones de sentido y de poderío (1999:16).

En tanto organizadoras de la vida cotidiana de las personas, las representaciones sociales, constituyen modalidades de pensamiento que reafirman relaciones de dominación que ubican a nativos y migrantes en determinadas posiciones dentro la configuración social.

\section{Unidad de Análisis y de Recolección de Información}

Como se ha explicitado ya, el objetivo de las entrevistas realizadas fue conocer las representaciones sociales que tenían los miembros del sistema judicial acerca de los migrantes externos - y sus derechos humanos - llegados a Argentina a partir de la segunda mitad del siglo XX. Las unidades de recolección fueron funcionarios judiciales de instancias nacionales, de la provincia de Buenos Aires y de la Ciudad de Buenos Aires. Se entrevistó a jueces, fiscales, secretarios, asesores tutelares, jefes de despacho, directores de áreas de denuncias y asistencia a la víctima, escribientes y prosecretarios. El número final de entrevistas (50) resultó de la implementación metodológica conocida como saturación teórica de la muestra, que Strauss definiera como el momento en el cual el crecimiento muestral no contribuye a nada nuevo al interior de las categorías de análisis.

La realización de entrevistas en un espacio como el judicial se fundamenta en la importancia que dicho poder tiene en la labor de garantizar el acceso a derechos de todos los seres humanos. Por otro lado, se debe hacer mención al rol que la Ley de Migraciones 25.871, sancionada en el 2003 y reglamentada en el 2010 otorga al Poder Judicial. La ley anterior, comúnmente conocida como "Ley Videla"3 se encontraba atravesada por la Doctrina de Seguridad Nacional que rigió en el país durante el último período dictatorial. Dicha ley se caracterizaba por criminalizar a los migrantes, regionales, fundamentalmente, y negar a los mismos su carácter de sujetos de derecho. La Ley 25.871 considera a la migración como un derecho humano y reconoce, al menos en la norma, una serie de derechos al migrante, igualándolo con el nativo. Este 
nuevo status del migrante como sujeto de derechos supone un avance sustancial frente a la legislación anterior. Desde muchos aspectos, la normativa actual se encuentra inspirada y atravesada por una perspectiva de derechos humanos ${ }^{4}$. Es en este escenario que adquiere importancia cuáles son las representaciones que los miembros de un sistema como el judicial construyen acerca del migrante y sus derechos.

\section{DIMENSIONES ANALÍTICAS: ACCESO A DERECHOS, CONCEPCIÓN DE CIUDADANÍA Y POLÍTICA MIGRATORIA}

Como se especificó en la introducción, en los próximos tres apartados se presentarán los resultados de la investigación a partir de tres dimensiones de análisis: Competencia entre nativos y migrantes en el acceso a derechos económicos y sociales; Concepción de ciudadanía restringida y Política migratoria anhelada.

\section{Competencia entre Nativos y Migrantes en el Acceso a Derechos Económicos y Sociales}

Los derechos humanos son interdependientes, integrales y universales. En este sentido, cuando el migrante es pensado, o al menos por su calidad de extranjeridad pareciera plausible de ser pensado, con cierto grado de "facilidad", como un sujeto al que puede negársele, delimitársele o dificultarle el acceso a determinados derechos, se evidencia la dimensión política necesaria para el cumplimiento de la retórica de los derechos humanos. En otros términos, para que no sean meras declaraciones de intención se hacen imperiosamente necesarias acciones que los garanticen.

La actual ley migratoria argentina ${ }^{5}$ iguala al migrante con el nativo respecto a la legitimidad del acceso a determinados derechos económicos y sociales. Así puede leerse:

El Estado en todas sus jurisdicciones, asegurará el acceso igualitario a los inmigrantes y sus familias en las mismas condiciones de protección, amparo y derechos de los que gozan los nacionales, en particular lo referido a servicios sociales, bienes públicos, salud, educación, justicia, trabajo, empleo y seguridad social. (Artículo 6)

En ningún caso la irregularidad migratoria de un extranjero impedirá su admisión como alumno en un establecimiento educativo, ya sea este público o privado; nacional, provincial o municipal; primario, secundario, terciario o universitario. Las autoridades de los establecimientos 
educativos deberán brindar orientación y asesoramiento respecto de los trámites correspondientes a los efectos de subsanar la irregularidad migratoria. (Artículo 7)

No podrá negársele o restringírsele en ningún caso, el acceso al derecho a la salud, la asistencia social o atención sanitaria a todos los extranjeros que lo requieran, cualquiera sea su situación migratoria. Las autoridades de los establecimientos sanitarios deberán brindar orientación y asesoramiento respecto de los trámites correspondientes a los efectos de subsanar la irregularidad migratoria. (Artículo 8)

De esta manera, en el texto de la ley, se acaba con las limitaciones a derechos, vinculadas a la situación de regularidad o irregularidad, impuestas por la anterior normativa a los migrantes externos para acceder a la salud, educación, justicia y seguridad social. Asimismo, la irregularidad no deberá ser denunciada por las autoridades de los establecimientos educativos, de salud, etc. sino que este tipo de situaciones, una vez detectadas, generarían una obligación de asesoramiento para la regularización del migrante, por parte de las autoridades correspondientes. Contrariamente a la Ley Videla, que instaba a denunciar este tipo de situaciones, la normativa en vigencia considera prioritaria que la respuesta estatal sea la regularización del migrante, para lo cual las diversas instancias estatales deben trabajar. Así, se consagra en el cuerpo de una ley local una serie de derechos humanos, especificados en normativas internacionales, pactos, declaraciones y protocolos, que ya habían sido firmados por Argentina y muchos de ellos incorporados a la Constitución Nacional en la reforma de $1994^{6}$, pero que eran objetados por la anterior ley que gestionaba las migraciones.

Ahora bien, respecto a la equiparación de migrantes y nativos las opiniones vertidas en las entrevistas presentan algunos acercamientos y distancias con la idea de universalidad, propias de la retórica de los derechos humanos. En las entrevistas pudo identificarse un gradiente de representaciones acerca del mayor o menor reconocimiento de los migrantes como legítimos portadores de derechos económicos y sociales. De esta manera, y sin olvidar - en la incidencia de las respuestas - que los entrevistados en cuestión son miembros de una institución en la que la igualdad (formal, muchas veces) ${ }^{7}$ se presenta como uno de los valores supremos, es posible evidenciar manifestaciones a favor del acceso de todos los migrantes que "ya viven entre nosotros" a derechos tales como la salud y educación pasando por aquellos que sostienen que los Estados de procedencia de dichos migrantes deberían solven- 
tar los "gastos" que sus poblaciones generarían a nuestro país, hasta finalizar con posturas que sostienen que la prioridad debe ser para los nativos ${ }^{8}$.

(...) te digo esto tiene que ser algo de más arriba, el ingreso tiene que regular pero, una vez que ya están acá dentro creo que la salud, la educación tiene que ser igual para cualquiera, no puede, si vos sos argentino te atiendo sino no, me parece que ahí tiene que ser igual porque son servicios de primera necesidad...una vez que ya está, por eso te digo, primero tiene que haber una regulación en el ingreso, pero una vez que pasen ese primer paso, ahí sí ya son iguales, son argentinos, ya está pueden ir a cualquier hospital como cualquier argentino, pueden ir a cualquier escuela pública como cualquiera (Secretaria, 5 años en el sistema judicial).

Yo entiendo que el Estado tiene que tener políticas activas para combatir la pobreza, en general, la pobreza. Después habrá que debatir la pobreza de dónde. (...) Convengamos, que si el Estado Nacional dice bueno, "yo voy a combatir la pobreza de Latinoamérica", bueno, eso va obviamente a necesitar de recursos, entonces, obviamente tendrá que haber acuerdos, porque nosotros no nos podemos hacer cargo de todos los pobres del mundo. (...) Hagamos acuerdos para decir "Bueno también para los países vecinos" "dame plata, dame medios" (Secretario, 14 años en el Sistema judicial).

(...) yo creo que nosotros estamos acá y pagamos los impuestos y tenemos que tener acceso a todo lo que nos pueda dar el Estado, más allá de que, bueno, o sea, puede pasar que o haya venido una persona o tenga familiares pero, yo te digo esto que vi el otro día en la Maternidad Sardá fue horrible porque venía gente de otros países y gente de acá, es una maternidad, un hospital excelente y gente de acá no puede tener acceso a este, porque está o gente de otros países o vienen..., o más que la gente que va a tener, los familiares van y aparte son muy oportunistas... (Empleada Administrativa, 2 años en el sistema judicial).

Al desagregar los nodos discursivos de los entrevistados se hacen evidentes - en muchos casos - representaciones sociales que ligan a los migrantes con categorías tales como "aprovechadores", "ilegítimos usuarios", "depredadores", "abusivos", es decir, como sujetos que demandan pero no aportarían nada positivo. Se establece, de esta manera, la imagen del migrante como un competidor desleal por los recursos estatales. La distancia, erigida a partir de la construcción de una otredad migrante negativa, coadyuva en la elaboración de un discurso limitante de los derechos humanos. La "lejanía" del extranjero - 
aunque espacialmente esté cerca, como es el caso - admite justificar "excepciones" a la igualdad en el acceso a derechos, o al menos a que esa excepcionalidad sea pensable.

En este tipo de discursos excluyentes subyace la recurrente imagen del extranjero como el culpable de todos los males. Diversas investigaciones ${ }^{9}$ han evidenciado que no debe buscarse en la presencia de extranjeros las causas de, por ejemplo, los niveles de desempleo. No obstante, discursos que culpabilizan a los migrantes por este tipo de problemáticas (fomentados muchas veces desde instancias "oficiales") ${ }^{10}$ han calado en la percepción común.

Sin lugar a duda pienso que sí, que debemos darles prioridad a nuestros ciudadanos, inclusive creo que nosotros debiéramos generar algún tipo de convenio para toda la atención sanitaria que hacemos a extranjeros tratar de cobrársela al país extranjero de alguna manera. Yo creo que primero hay que atender al Argentino y después hay que atender al migrante, que por supuesto las emergencias hay que atenderlas siempre sin ningún lugar a duda, eso desde ya, y creo que habría que generar algún tipo de convenio para tratar de cobrarle al país, al país extranjero. La incidencia es casi de un $60 \%$. Y en educación también es importante. $Y$ es un impacto presupuestario muy importante, que es una realidad que no se puede obviar ¿Qué vas a hacer? ¿Le vas a decir váyase a su casa? No se puede hacer. Hay que tratar de generar un convenio o algo, algún tipo de acuerdo para que aunque sea una parte se hagan cargo, sobre todo teniendo en cuenta que si uno va a su país no tenés la misma recepción, ¿no? (Secretaria Judicial de derechos y garantías, 2 años en el sistema judicial).

Precisamente, porque somos los que tenemos que tener primer cobija del Estado y después, por supuesto que los demás sí, pero pasa en todos lados del mundo, creo que por reciprocidad, si vas a España y te querés hacer atender en el hospital si no tenés la tarjeta social porque no pagas impuestos, que sé yo, no te van a atender y si vas a cualquier otro país, pasa lo mismo, estamos hablando de países del primer mundo, y si vas a Bolivia, Paraguay, cualquiera, va a pasar lo mismo, pero acá por ejemplo, vas a un hospital y van personas de diferentes partes de Latinoamérica a atenderse y porque es gratuito y porque y ni siquiera demuestran que viven acá (Fiscal 10 años en el sistema judicial).

En suma, sea la legislación migratoria caracterizada como integradora, como puede considerarse a la actual Ley Migratoria argentina, o más bien restrictiva, como las de países como Italia, Alemania o Estados 
Unidos, la asociación ciudadano/nativo continúa siendo primigenia en los imaginarios de sociedades que han construido sus lazos de solidaridad a partir de la identidad nacional como principal referente, sobre todo cuando implica el reconocimiento de derechos. En ese considerar "prioritaria" la asistencia de los nativos, dada la idea de la "finitud de los recursos estatales", los extranjeros pueden ser considerados ciudadanos de segunda categoría y verse relegados frente a la "necesidad" de los nativos. De este modo, la cuestión no puede analizarse observando solo las normativas. Un análisis de los imaginarios presentes en el sistema judicial resulta un aporte sustancial. No debe olvidarse además que, si bien dicho sistema no puede decir cuáles son las medidas que desde las instancias estatales de ejecución de políticas públicas deben llevarse a cabo, sí puede instar a efectuarlas, delimitar las "zonas grises" de la administración pública y señalar cuando la actuación administrativa va en contra del sistema jurídico general (Abramovich y Courtis, 2006).

En este sentido, la concepción de universalidad de los derechos humanos interpela a los miembros del sistema judicial a pensar al migrante como un igual. No obstante, como vemos, persiste en gran parte de los testimonios de los entrevistados una visión excluyente. Continúan siendo los nativos los que deberían decidir si otorgar "generosamente" derechos, cuáles y hasta qué punto. Son los nativos, por medio de sus instancias estatales, los que deciden qué ceder, qué reconocer a los extranjeros (que no son considerados como titulares de derechos sino tan solo como meros beneficiarios de la "bondad" del dadivoso Estado Nacional) y qué exigirles, porque, desde la perspectiva de los entrevistados, después de todo "nosotros" somos los miembros legítimos de este Estado nación. Ello nos lleva al tema del próximo apartado: la concepción de ciudadanía.

\section{Concepción de Ciudadanía Restringida}

Si realizamos un recorrido histórico sobre los derechos, los mismos (excepto los políticos) fueron declamados como universales. Sus titulares eran las personas ${ }^{11}$. Claro está que se trataba de épocas en que los habitantes de las potencias se trasladaban hacia los países que habían colonizado. Con el progresivo desarrollo de las organizaciones estatales, se subsumirían los diversos modos de existencia e identidad a la lógica nacional (Hobsbawm, 2004). Hoy día, invertido el sentido de los flujos migratorios, la situación pareciera ser diferente y la lucha por 
los derechos pretende fundarse sobre la ciudadanía, concepto que ya no resulta inclusivo, sino todo lo contrario. La universalidad y reciprocidad de los derechos de residencia y de libre circulación ha sido negada y “(...) los derechos se han convertido en derechos de ciudadanía, exclusivos y privilegiados (...)" (Ferrajoli, 1999:118) ligados a un Estado nación y a su territorialidad.

Es decir, las nacionalizaciones de las sociedades, propias del desarrollo del sistema capitalista, han asimilado la idea de ciudadanía con la pertenencia nacional. Ello ha repercutido también en las estructuras jurídicas y de reconocimiento de derechos. De este modo, el "derecho a tener derechos" aparece asimilado a la categoría de ciudadano (Arendt, 1998). Consecuentemente, la categoría de ciudadanía se reactualiza de forma continua y en función de los intereses a preservar. Frente a la idea de los derechos como bienes escasos que deben resguardarse reaparece el migrante como "chivo emisario" entendido como el causante de problemáticas tales como altos índices de desempleo, inseguridad, deterioro de servicios públicos, etc. La pertenencia ciudadana posibilita establecer un límite a la universalidad de derechos. El Estado en pleno ejercicio de su soberanía será el encargado de determinar dicho límite.

(...) yo creo que primeramente no puede, si bien la realidad, el Estado no termina de ver la forma para contener el gran índice de pobreza que hay. Sería por ahí absurdo, pretender que controle no sé, a la situación de pobreza del extranjero. Yo lo que creo que deberían controlar mucho más el sistema migratorio porque, porque el sistema migratorio descontrolado, repercute en la cuestión delictiva, en la cuestión de salud. Que no hay un control exhaustivo a las personas que vienen de otros países en cuanto a salud. Que no necesariamente pueden tener una enfermedad, pero bueno, pueden traer otra, digamos, otras condiciones que acá no se perciben. Entonces creo que es fundamental, toda la legislación y la normativa que tenga que ver con el control inmigratorio (Secretaria, 15 años en el sistema judicial).

(...) yo pienso que primero el país le tiene que dar prioridad y todos los derechos y accesos a los ciudadanos nacidos en él. Una vez que cumple eso bueno, poder dar acceso a los limítrofes. Pero primero el país se tiene que dedicar a sus habitantes me parece. Y bueno, la verdad que es muy feo lo que te... es un poco lo que te estoy diciendo, ¿No? Sé efectivamente que gente de países limítrofes viene a Argentina a hacerse atender porque en algunos hospitales, no en todos, pero en algunos 
hospitales, Argentina brinda un muy buen servicio; y tenemos muy buenos médicos. Entonces se sabe que vienen extranjeros a atenderse acá. También se sabe que hay muchos argentinos que se les dificulta, por más que el acceso sea gratis, se les dificulta, que no consiguen turnos... y bueno, si a un argentino le tardan un mes en darle un turno que es urgente y resulta que hay cien bolivianos que están antes, que me parece que no corresponde, a mí me parece que no corresponde. O sea me parece que tienen que... o sea, ¿Por qué Argentina tiene que brindar un servicio que no lo brinda Bolivia, por ejemplo? ¿Por qué? Nosotros tampoco somos una potencia económica como para decir "no, Argentina es un país súper poderoso", nosotros somos del tercer mundo también. Tenemos una de las peores economías... o sea ¿Por qué nosotros tenemos que estar sustentando lo que no hacen tampoco los países de al lado? (Secretaria, 20 años en el sistema judicial).

En términos de Bauman (2005), el extranjero carga con el estigma del pecado de la llegada tardía. Su no pertenencia "desde siempre" estructura lo que es y a lo que puede aspirar en la comunidad nacional receptora. En la cotidianeidad de las personas, la identificación nacional se sustenta en su carácter político pero también en elementos culturales que se evidencian, desde la perspectiva nativa, como "naturales" y que aúnan a los miembros de la comunidad. La reproducción de ese imaginario nacional se torna imprescindible para el mantenimiento del status quo. El nudo del conflicto se presenta cuando el migrante, con su sola presencia, evidencia la arbitrariedad de criterios de diferenciación al comportarse como un sujeto que exige visibilidad, participación y reconocimiento. En ese momento, las fronteras materiales (como podremos analizar en el apartado que sigue) pero también las de tipo simbólicas son esgrimidas por los nativos como lo suficientemente evidentes para establecer quiénes son los "verdaderos nacionales" y quiénes no. El paso siguiente a este razonamiento, basado en la identidad nacional apoyada en en dos polos, "etnicidad ficticia" y "patriotismo" (Balibar, 2005), habilita el pronunciamiento de discursos excluyentes, muchas veces disfrazados con argumentos que remiten a la existencia de recursos escasos por parte del Estado.

(...) me parece, sin digamos, sin caer en una propuesta, digamos, discriminadora ${ }^{12}$, ni negativa al respecto, pero, es una realidad. Si vos tenés un aparato saturado, porque, digamos - hacemos agua, por todos lados -, permitir el ingreso de gente, que a lo mejor, por una proyección vos crees que va a formar parte de esa clase más vulnerable, me parece que debería ajustarse un poco (Prosecretario, 7 años en el sistema judicial). 
El desarrollo de la globalización y de la mundialización económica trae aparejado procesos de debilitamiento de algunos Estados y el fortalecimiento de otros. Las asimetrías entre países ricos y pobres se acentúan y parecieran socavar el poder soberano de los Estados más "débiles." De este modo, hay Estados mejor y peor posicionados en el escenario internacional, y las respuestas que los mismos pueden dar a los desequilibrios económicos, políticos y sociales al interior de sus fronteras se ve influido por su capacidad de acción y posicionamiento global.

En relación a las respuestas sobre la problemática migratoria, cada Estado define su política. El poder soberano no se presenta debilitado en ese aspecto. Asimismo, frente a procesos de crisis se produce un robustecimiento de las exigencias que los nativos dirigen a éste en relación al diseño y gestión migratoria. Una alteridad migrante, sobre todo si proviene de un país "pobre", será fácilmente culpabilizada por flagelos sociales (como la desocupación, la inseguridad, etc.) que exceden al poder de acción de nativos y de extranjeros. En esos momentos de crisis es que el nacionalismo, por su paradojal carácter creador de lazos sociales y, a su vez, limitante de los mismos, resulta ser aun efectivo.

Creo que el Estado debería implementar políticas que atiendan la condición de pobreza de todos los habitantes. No solamente de los migrantes y creo que primero debería ocuparse de los argentinos y en todo caso después de los migrantes. Los migrantes tienen un montón de beneficios que nosotros como migrantes en otros países no tendríamos, que les provee el Estado como ser educación en las mejores universidades, en la Universidad de Buenos Aires, por un costo menor que el que ellos pagan en su propio país. Entonces creo que el Estado debería primero ocuparse de políticas tendientes a disminuir la pobreza de las personas argentinas. Y en todo caso después, sí, no me parecería mal que aplique lo mismo a los migrantes. Y yo creo que teniendo en cuenta que los recursos son escasos, frente a la presencia de la población extranjera, el Estado debería priorizar a sus ciudadanos frente a la población extranjera. Que no es una cuestión, digamos de discriminación ni una cuestión de exclusión del extranjero. Pero creo que vivimos en un país en el que hay muchas personas argentinas que no tienen posibilidades de absolutamente nada y que puede ser que producto de ello terminen iniciándose en el ámbito delictivo (Jefa de Despacho, 7 años en el sistema judicial). 
En términos de Anderson (2002) "... el fin de la era del nacionalismo" anunciado durante tanto tiempo, no se encuentra ni remotamente a la vista". La doble ilusión de la identidad nacional, dada por la idea de "proyecto" y "destino", que comparten todos los miembros de la comunidad nacional, de las que nos habla Balibar (2005), sigue fuertemente arraigada en los imaginarios de las sociedades. En consecuencia, si bien, la idea de identidad nacional se encuentra en un proceso de crítica y crisis en el ámbito de las ciencias sociales (hablándose ya no de identidad sino de identidades o de identificaciones), manifestándose así el carácter inventivo sobre el que reposa la "comunidad nacional", el efecto de realidad que la misma posee aún hoy, a nivel de la estructuración de las relaciones del mundo cotidiano, no puede ser negada. Es decir, la efectividad de "los mitos del origen nacional" (Balibar, 2005) continúa operando.

El relato que vincula de modo "natural" a los nativos y que, en contraposición, desplaza a los migrantes de la sociedad receptora o de destino es lo que subyace a los modos de calificar y clasificar lo que el Estado tiene de sus habitantes. Las modalidades de exclusión e inclusión que supone toda lógica calificadora y clasificatoria efectuada por el Estado nación legitima "naturalezas de personas" que justifican "tratamientos de exclusión", productores de efectos que demuestran la "verdad de la naturaleza" postulada (Pacecca, 2006). El carácter de "Otro" del migrante se impone como un dato objetivo. No es pensable su cuestionamiento. Subyace un razonamiento basado en una esencia erigida fundamentalmente en las fronteras geopolíticas y reproducidas a partir del reforzamiento de las fronteras simbólicas erigidas a partir del prejuicio, del imaginario social, de las representaciones sociales de los nativos.

La otredad casi absoluta de extranjero, anclada y objetivada en la evidencia de su no naturalidad, es un poderoso pero vacío campo de fuerza cuyos contenidos varían (...) pero siempre trazadas a esa esencia que es otra, a esa naturaleza que es otra, a esa nacionalidad que es otra. (...) la otredad aparece como un recipiente natural, como una forma que no precisa demasiada argumentación (Pacecca, 2001).

En la definición que se hace del "otro" migrante subyace una lógica de inclusión y exclusión. El migrante, en su calidad de forastero ${ }^{13}$, es plausible de ser reprochado por su "dudosa lealtad", estableciéndose una diferenciación por el carácter de "llegada tardía"14 que porta el migrante como estigma. En suma, la pertenencia a la comunidad nacional 
continúa siendo efectiva en la estructuración de la constitución de identidad y el establecimiento de lazos de solidaridad entre quienes se piensan como miembros de dicha comunidad. Asimismo, el imaginario de pertenencia habilita discursos y prácticas que excluyen. Aquí se entiende que:

(...) cuando hablamos de exclusión decimos que es una forma de decir, de pensar y de actuar coercitiva sobre el otro. (...) las acciones con las cuales se excluye, no tienden solo a separar, excluir es además limitar, acotar, obstaculizar al otro, en otras palabras, es pautarle un orden. El sujeto es excluido en sus posibilidades de participación (...). Excluirlo es coartarlo en su posibilidad de constituirse como sujeto libre, con derechos y obligaciones. El excluido está, no se lo destruye, es un cuerpo que existe, que convive con su agresor, pero limitado en sus capacidades de elegir (Cohen y Mera, 2005:150-151).

En las entrevistas resulta evidente que los sujetos a excluir serán todos aquellos nacidos del otro lado de la frontera nacional, siendo señalados fundamentalmente los que provienen de Paraguay, Bolivia y Perú. Paradójicamente, los procesos de regionalización tienden a instar a los Estados nacionales a una apertura mayor respecto a quienes quedarán dentro y quienes fuera del proceso de cierre propio de este tipo de proyecto político y económico regional. Por ejemplo, el plan para un Estatuto de Ciudadanía del Mercosur (Decisión 64/10), aprobado en diciembre de 2010, contempla el reconocimiento de un catálogo de derechos a las personas nacidas en los países de la región. Eso ocurre de forma análoga a la Ley argentina no 25.871, en la cual los derechos sociales como la salud, la educación y el trabajo son considerados centrales.

No obstante, también el planteo respecto al reconocimiento de esos derechos en función de una ciudadanía, no ya nacional, sino regional vuelve a contradecir el carácter universal de los Derechos Humanos.

La reciente iniciativa del MERCOSUR hace alusión de manera exclusiva a los nacionales procedentes de los Estados Miembros, al momento de proponer un estatus de ciudadanía regional que estaría acompañado del derecho a la libre circulación y a la igualdad de derechos (sociales y políticos) con los nacionales de los países de destino. Tal vez, reproduciendo un modelo de regulación de las migraciones - el europeo - iniciado hace unos veinte años, sobre el cual se ha verificado ampliamente su ineficacia y especialmente su drástica desconexión con prin- 
cipios elementales de derechos humanos, parecería no haberse comprendido debidamente la relación entre esa realidad y la creación de una ciudadanía excluyente (Ceriani Cernadas, 2012:117).

Los riesgos de una definición limitada de ciudadanía se vinculan con el derecho a migrar y el acceso a ciertos derechos sociales y políticos basados en la nacionalidad. De este modo, análogamente a lo que plantea la definición del ciudadano comunitario, la lógica de inclusión y exclusión es contraria al principio de universalidad propia de la doctrina de derechos humanos. Asimismo, este tipo de "construcciones jurídicas" repercute en el modo en que se construye representacionalmente al extranjero. Santamaría (2010) plantea, por ejemplo, que la inclusión de España en la Unión Europea implicó la invención de una "nueva figura de alteridad": el migrante extracomunitario. De manera que, la construcción jurídica se ve retroalimentada por una representación social acerca de un "sujeto inmigrante bueno/auténtico y el inmigrante inauténtico/sospechoso" (De Lucas, 2003 citado en Zamora, 2005:60). Es la sociedad europea la que construye a la inmigración no comunitaria dándole ciertas características que no le son propias ni inherentes a ella. La idea de la migración extracomunitaria como "problema social" radica más en lo que la sociedad receptora elabora sobre ella que en lo que la misma genera. Algo similar puede pasar en el caso de la construcción de la ciudadanía regional del MERCOSUR.

De esta manera, legislación e imaginario se configuran y se reconfiguran históricamente. Al respecto, Domenech entiende que en Argentina "...así como la inmigración es construida como problema fundamentalmente a partir de la ilegalidad que se le adscribe, la ilegalidad estructura la visión de Estado (...) sobre la inmigración contemporánea (...)" (2011:33). Es decir, el modo como se ha vinculado históricamente en el país a los migrantes como sujetos "ilegales" presenta un nivel de continuidad que llega hasta nuestros días y que se percibe en los modos en que las distintas administraciones gubernamentales, leyes y otras instancias gubernamentales han concebido a las migraciones.

Asumir una perspectiva que priorice los derechos humanos de las personas, desechando una lógica instrumental de las migraciones, requiere subvertir modos de pensar arraigados históricamente en diversas instancias estatales ${ }^{15}$ y regionales que responden a necesidades de los mercados internacionales reguladores de la movilidad de capitales y personas. Cuando la tensión entre ciudadanía nacional y reconoci- 
miento de derechos de aquellos nacidos más allá de las fronteras estatales nacionales es reactualizada, la mentada universalidad de la perspectiva de Derechos Humanos pareciera ser puesta en jaque.

Entre las medidas estatales que se vinculan con el reconocimiento y el establecimiento de garantías para que los migrantes accedan a derechos fundamentales de modo universal se encuentran las políticas migratorias, que entendidas en un sentido estricto, suponen las decisiones referidas al ingreso, egreso y condiciones de permanencia de los migrantes. Sobre esa dimensión trata el siguiente y último apartado de análisis.

\section{Política Migratoria Anhelada}

Tras la sanción de la Ley 25.871 se le encomienda al Poder Judicial una serie de funciones y obligaciones en relación a la política migratoria en el sentido restringido antes mencionado. Así, frente a la posibilidad de expulsión de un migrante debe darse intervención a la instancia judicial. Con la anterior legislación ello no ocurría ${ }^{16}$. Ahora el migrante adquiere el status, al menos legalmente, de sujeto de derechos, debiéndose cumplir con todas las garantías procesales implicadas ${ }^{17}$. Por ello, resulta importante conocer cuáles son las representaciones sociales que los miembros de dicho sistema tienen acerca de la política migratoria de nuestro país: cuál es la que creen que se encuentra vigente, cuál conciben sería la más adecuada, qué simetrías y asimetrías tiene con la que se propone a partir de la actual ley. En definitiva, el análisis de las representaciones, acerca las políticas migratorias, interesa por su vínculo con aquellas que refieren al acceso y respeto de los derechos humanos de los migrantes.

El primer dato relevante respecto a este tema es que los entrevistados, en casi su totalidad, hacen referencia a la ausencia de políticas que regulen, por parte del Estado, las migraciones ${ }^{18}$.

- No está en la orden del día.

- ¿El tema de la política migratoria?

- Sí. Me parece que las cosas se están improvisando, digamos. No es que se hace con un fin determinado. Tenemos, digamos, tantos baches por tapar, que me parece, que bueno, que no hay una política interesante, en este sentido, ni hecha a conciencia. A mí me parece que (...) se deja ingresar gente, que el ingreso no va a depender de nuestra política, sino de una cuestión de azar, o de estimulación. O sea, el que viene, a lo me- 
jor, viene porque tiene algún familiar, o algo. De acuerdo al bienestar que tenga esa persona que se radicó acá, podrá difundir, la conveniencia o no, de venir hasta Argentina, digamos. A mí me parece que acá se actúa ya cuando el resultado, digamos. Una vez que está acá bienvenido, bueno, iniciará sus trámites de radicación, después se documentará (Prosecretario, 7 años en el sistema judicial).

Se percibe en el testimonio anterior una demanda hacia el Estado no solo de control de las migraciones sino de gestión de las mismas. En otras palabras, se trata de un pedido de que el Estado administre el flujo de migrantes y que lo haga de modo preciso. Se insta entonces a un enfoque que persiga un "tratamiento" de las movilidades internacionales que las gobierne, procurando fundamentalmente controlar sus consecuencias consideradas todas o casi todas negativas para la sociedad receptora. Estas exigencias se arraigan en la creencia, también evidente en las entrevistas, del des-control de las migraciones dada la supuesta capacidad de agencia del migrante. Las migraciones son vistas así por miembros del sistema judicial como efecto de la decisión personal, deliberada y libre del extranjero. No interesa aquí debatir sobre si esta cuestión es real o no (porque ello implicaría otro tipo de investigación, universo de estudio y estrategia teórico-metodológica) ni es intención sugerir que el extranjero carece de todo poder de decisión, tan solo importa resaltar - dada la perspectiva de la investigación de la que se nutre este artículo - cuál es la visión de los miembros de la institución analizada: se trata de una mirada que considera a las migraciones como fundamentalmente producto de iniciativas personales y / o familiares del extranjero frente a la cual el Estado parece reaccionar "tar$\mathrm{de}^{\prime}$, esto es regularizando o "legalizando" al migrante que ya se encuentra "entre nosotros". Queda claro que la "ausencia de política migratoria" a la que se refieren los entrevistados simula en realidad la exigencia de una modalidad de gestión de los flujos migratorios que tienda hacia su endurecimiento.

Y ahí el Estado, no sé qué tendría que hacer. En realidad la política migratoria del Estado parece estar más confusa y más incierta. La verdad que no se bien para qué lado apunta el Estado (...). La política del Estado debería ser, por lo menos, un poco más firme, en un sentido o en otro y cumplirse. Yo creo que el país, además de una política migratoria, tendría que tener una política estratégica bastante más grande: población falta, pero la que hay está mal distribuida. Hay muchísimos recursos poco explotados, y encima la gente se va concentrando nada más en Bu- 
enos Aires... digamos que somos un país muy grande en territorio, y chico en población. O sea que la inmigración, en principio, debería ser bastante bien recibida, y sin embargo no hay una estrategia para contener esa inmigración y para dar un cauce eficiente, pero bueno, es una cuestión, me parece, que todavía no está definida. Para mí, el Estado debería, desde una política de Estado, a largo plazo, que...involucra sí o sí la política migratoria. Pero bueno, por ahora parece que no pasa nada (Prosecretaria, 23 años en el sistema judicial).

La opinión de los entrevistados - que supone la indiferencia que el Estado mostraría frente a la problemática de las migraciones - oculta una perspectiva en la que se interpela a las autoridades estatales a que asuman una postura de mayor rigidez que se traduzca en medidas restrictivas, que restrinjan la entrada, que controlen quiénes ingresan y por qué, que seleccionen a aquellos que migran con el objetivo de "aportar" a la comunidad nacional. De esta manera, la migración adquiere un carácter instrumental o funcional. El migrante es reducido a una mercancía y, por tanto, él debe justificar su presencia; convertirla en necesaria, fundada, correcta, justa, precisa, normada, organizada, ordenada, legal.

Totalmente, el ingreso, tiene que pedir más requisitos para que ingresen, cerciorarse que vienen a trabajar, en qué condiciones van a trabajar, si es que vienen de turismo, si es que vienen a quedarse, eso lo tiene que regular el Estado, lo tiene que regular y no lo regula, hoy en día entra cualquiera acá, y cualquiera tiene un trabajo en negro y eso es lo que regula y provoca que el argentino esté sin trabajo porque el empleador evalúa por ahí, entre tomar a un boliviano que te cobra 10 pesos la hora en un trabajo, a lo que debería cobrar por reglamentación argentina una persona común, elige...elige a su conveniencia, que está mal porque el día de mañana le pasa algo a esa persona que está en negro y bueno...pero se arriesgan de hecho todas las cosas que vemos en la tele hasta que alguien denuncia y salga todo a la luz (Secretaria, 5 años del sistema judicial).

En este sentido, el migrante no es ya visibilizado como aquella persona a la que se le niegan derechos (por ejemplo, jornadas de trabajo bajo el marco legal, salarios justos y condiciones laborales dignas en general) sino como fuerza de trabajo que se vende "barata" y que resulta "conveniente" para el empleador aunque ello implique infringir normativas laborales instituidas. 
En suma, a dicha perspectiva instrumental acerca de los migrantes se adiciona la cuestión del pecado original del que nos habla Bauman (2005) y que se refiere a la no pertenencia del extranjero "desde siempre" al colectivo de nativos. Es así que el migrante debe probar in eternum su "lealtad" a la comunidad nacional para ser merecedor de lo que le otorga dadivosamente el Estado y ni aun así lo logrará del todo jamás. Dos son los elementos a considerar en este punto: la cuestión de la temporalidad y la de la territorialidad. Es decir, el migrante para acreditar su lealtad debe "vivir entre nosotros" y además hacerlo desde hace cierto tiempo. Claro está que son los Estados (en su ejercicio soberano) los que establecen esos criterios. El primero a partir de la delimitación fronteriza y el segundo por medio de legislaciones que especifican los años de residencia exigidos para unos y otros derechos.

Asimismo, entre los motivos acerca de la urgencia de delinear una política migratoria restringida, los entrevistados refieren a la incapacidad del Estado nacional para satisfacer los derechos de los nativos. Es decir, si se disminuye el número de migrantes se reducirá también la exclusión de los nativos a determinados derechos económicos y sociales. Es en este punto que los discursos que apelan al enemigo externo y a la unidad nacional renacen. Es el Estado Nacional el que es interpelado para asegurar - vía una política migratoria que ordene y regule la entrada del "aluvión" de extranjeros - el acceso de sus ciudadanos nacionales a sus derechos fundamentales. Nuevamente, se disuelve y transmuta el conflicto entre clases por el conflicto entre miembros "legítimos" de la comunidad nacional (nativos) y los que no son parte "desde siempre" de la misma (migrantes). En ese contexto, la eficacia de la idea de la comunidad imaginaria de nación y su concreción a partir de medidas precisas del Estado se entrelazan. El éxito de esa idea de comunidad se arraiga en una serie de representaciones sedimentadas, ancladas en el imaginario social. Tal como plantea Pérez-Agote (1993:8)

(...) puede decirse que la eficacia social de las ideas, representaciones y definiciones de la realidad es su capacidad para determinar o influenciar el comportamiento de los actores sociales; esta capacidad no depende en un principio (no tiene por qué depender) de su mayor o menor "objetividad científica"; más bien depende del mayor o menor grado de evidencia social que alcance, es decir, de su mayor grado de "objetividad social", en el sentido de lo que está socialmente reconocido de forma compartida. 
De modo que, dichas representaciones sociales acerca de los migrantes se articulan con la idea de frontera geopolítica, logrando quebrar la retórica de la universalidad y de la igualdad de derechos planteada, en algunos casos, entre los entrevistados. Frente a la evidencia de la no pertenencia natural del migrante al colectivo nacional, es posible enunciar un discurso excluyente que se traduce en una política migratoria basada en estrategias que regulen, controlen, direccionen, en fin, conviertan en manejables los flujos migratorios. La relación con el migrante se entabla, en ese momento, en términos instrumentales, es así que su presencia no es legítima y, por tanto, debe ser legitimada porque "...es la presencia que solo puede ser pensada y concebida, percibida y experimentada como presencia vista de..., a fin que..., en razón de..., a causa de..., en tanto que..., etc." (Saiad, 2009:104).

Finalmente, cabe reiterar que, en relación al diseño de políticas migratorias, desde hace algunas décadas, se incorpora la idea de gestión antes que la de control (Domenech, 2011; Sassen, 2013; Blanco, 2006). Esta línea se presenta como dominante, al menos discursivamente, no solo a nivel de Argentina sino también a nivel de instituciones e instrumentos internacionales que pronuncian que:

Uno de los principios rectores de la gobernanza de la migración debe ser la garantía de que todos los migrantes, cualquiera sea su situación de inmigración, puedan disfrutar de sus derechos humanos internacionalmente reconocidos en todas las etapas del proceso migratorio en países de origen, de tránsito y de destino (Informe del Relator Especial sobre los Derechos Humanos de los Migrantes del 3 de agosto de 2010).

No obstante, resultan inquietantes las distancias entre estos pronunciamientos y las representaciones sociales que los miembros del sistema judicial tienen acerca de los migrantes. Cabe preguntarse entonces: $¿ E s$ posible de-construir una modalidad de relación entre los extranjeros y los miembros de la sociedad receptora que no se base en el cálculo instrumental? ¿De qué manera es factible la justiciabilidad y accesibilidad de derechos por parte de los migrantes internacionales con un sistema judicial en el que persisten representaciones sociales acerca de las migraciones, los derechos económicos y sociales, la política migratoria, etc. como las reseñadas a lo largo de estas páginas?

\section{CONCLUSIONES}

Retomando las dimensiones de análisis especificadas al comienzo del artículo (política migratoria anhelada, competencia entre nativos y mi- 
grantes en el acceso a derechos económicos y sociales y concepción de ciudadanía restringida) pudo evidenciarse que a nivel representacional se construye al "otro" migrante como una carga que se preferiría no tener, se lo vincula además a una imagen del extranjero como escasamente merecedor de determinados derechos (sociales y económicos, fundamentalmente) frente el nativo.

Asimismo, dadas las características de los entrevistados-conocedores de la ley y de las doctrinas de Derechos Humanos -, esta visión se traduce en dos posibilidades: entrevistados que sostienen la importancia de priorizar a los nativos porque "nosotros estábamos primero" o porque "acá hay mucha pobreza" y aquellos que consideran que el acceso a los derechos debe ser y es igual para todos, tanto para nativos como para migrantes, pero solo para aquellos que ya viven "entre nosotros". Entre ambos tipos de entrevistados, se presenta como una necesidad el desarrollo de una política migratoria más restrictiva que atentaría contra el derecho humano a migrar. Específicamente, en la primera de las dimensiones analizadas, resulta contundente la presencia de un imaginario nacional, como elemento representacional, que habilita el establecimiento de fronteras con los extranjeros. Por otra parte, si bien la "pobreza" como fenómeno social no es menospreciada por los entrevistados, todos consideran que es una de las funciones principales del Estado ocuparse de dicha problemática. No obstante, subyace de modo explicito e implícito a los discursos reseñados el interrogante: ¿la pobreza de dónde? De modo categórico, uno de los entrevistados responde: "Nosotros no nos podemos hacer cargo de todos los pobres del mundo". En esta oración, se resumen una serie de cuestiones centrales para aprehender de modo un poco más acabado los límites (materiales y simbólicos) que una perspectiva de Derechos Humanos verá aparecer y reaparecer continuamente en relación al reconocimiento de los migrantes como titulares de derechos. La lógica estatal nacional continúa operando, el trabajo de nacionalización de las sociedades ha sido tan bien logrado que persiste aun frente al florecimiento de instancias e instituciones internacionales de Derechos Humanos, de la retórica de las sociedades multi-interculturales y los discursos acerca del mundo global sin fronteras.

A nivel micro, los entrevistados sostienen que "nosotros estamos acá y pagamos nuestros impuestos y tenemos que tener acceso a todo lo que nos pueda dar el Estado". Es decir, los migrantes, como plantea Sayad, entre otros atributos, se caracterizan por su "presencia eventual", están hoy 
pero mañana podrían no estar. Asimismo, su estadía, por su calidad de "eventualidad", desde la perspectiva de la sociedad receptora, supone un escaso compromiso que se traduce, por ejemplo, en el no pago de los tributos que, como ya lo han establecido los politólogos en sus escritos sobre las conformaciones de los Estados, es uno de los elementos esenciales del "contrato social" de quienes forma parte de una unidad nacional. Este prejuicio acerca de los migrantes como sistemáticos evasores de impuestos es uno de los tantos que persisten acerca de los extranjeros y de los más simples de derribar si se considera el sistema regresivo de impuestos que existe en Argentina. Es así que, resulta imposible evadir impuestos para los migrantes que viven en el territorio dado que cada compra que realizan implica un aporte directo al fisco. Por otro lado, los migrantes de países limítrofes fundamentalmente, aportan cotidianamente con su trabajo, muchas veces mal remunerado y perteneciente a sectores informales de la economía, al Producto Bruto Interno del país.

De esta manera, el argumento acerca del migrante como no aportante y aprovechador de las riquezas del país es fácilmente derribado, no obstante el mismo resulta funcional para ocultar y disimular las causas estructurales de una distribución inequitativa de aquellas riquezas al interior de la comunidad nacional. Ello se vincula con aquel otro preconcepto acerca de la presencia supernumeraria de extranjeros, al decir de un entrevistado, en relación al uso que los extranjeros hacen de los servicios de salud y educación públicos: "es un impacto presupuestario muy importante". Lo cierto es que el número de extranjeros se ha mantenido en alrededor del $4 \%$ en relación a la población total de habitantes del país desde hace décadas, es por ello que los déficits en la atención y deterioro de ambos sistemas (salud y educación) no pueden ser explicados por un "aluvión" de migrantes que los "invaden". Nuevamente, es en las políticas económicas de los diversos gobiernos donde deben buscarse las causas de este tipo de problemáticas, pero nuevamente, el extranjero como "chivo expiatorio" resulta conveniente.

En el entramado de dicha lógica de culpabilización de la otredad, es pensable para los entrevistados considerar que debe predominar una "estratificación de la ciudadanía", es decir, resulta deseable y decible manifestar que el Estado establezca prioridades, aunque no entre sujetos según su clase social, sino entre quienes son nativos y aquellos que no lo son: "Primero el país le tiene que dar prioridad a todos los derechos y acceso 
a los ciudadanos nacidos en él". "Primero debería ocuparse de los argentinos $y$, en todo caso, después de los migrantes".

Las clasificaciones binarias de nativos y migrantes refuerzan el establecimiento de niveles de merecimiento de uno y otro grupo. De esta manera, en instituciones (como la judicial) se refuerzan relaciones de dominación entre nacionales y extranjeros que se encuentran dispersas en el entramado social en general. Las categorías de espacialidad y temporalidad (el migrante como siempre eventual ausente/presente) se imponen en la construcción cotidiana del imaginario social acerca de los migrantes. Consecuentemente, a pesar de los procesos de transnacionalización y mundialización de los derechos humanos, "lo local" obtura, limita y coarta modos de concebir a los ciudadanos de una manera más amplia e inclusiva que la nacional. En suma, ciertas narrativas, como la de la ciudadanía nacional “...albergan una tensión inherente entre inclusión y exclusión pues, junto con las propuestas morales y cognitivas en las que se basan sus estrategias de identificación y pertenencia, parecen verse obligadas a producir al mismo tiempo su antítesis..." (Terrén, 2003:142). En términos del autor citado, se trata de la "ironía de la solidaridad", es decir, por un lado, se crean lazos entre los nativos y, por el otro, se establecen barreras con los extranjeros. Esta idea, vinculada con los procesos de constitución de identidad, no impugnan el interrogante acerca de por qué son los migrantes (específicamente, cierto tipo de aquellos: pobres y sudamericanos) los que ocupan ese lugar de extraños y con respecto a los cuales se erigen fronteras. Es decir, si bien todas las comunidades definen su propia identidad en relación/ oposición a la otredad, quienes ocupan esa posición varía. Asimismo, como puede evidenciarse en las entrevistas, la mirada que los nativos construyen acerca de los extranjeros se encuentra cargada de sentidos: percepciones acerca de la pertenencia de clase de los migrantes, acerca de sus países de origen, sobre sus características culturales y morales, en fin, sobre la identidad de los mismos, calificando y clasificando su otredad.

Discursivamente, unida a esta idea de estratificación social y jerarquización de sujetos migrantes, aparece aquella que sostiene la importancia de endurecer la política de ingreso y permanencia de extranjeros. Desde la perspectiva de los miembros del sistema judicial consultados, esta sería la solución "ideal", ya que permitiría evadir la decisión acerca del reconocimiento del migrante como un igual. La no-presencia "entre nosotros" del extranjero, mantenerlo al margen de "nuestro" espacio físico, permite desentenderse de pensarlo como un sujeto titular 
de derechos. Asimismo, la política migratoria aparece ligada a la idea de gestión y supervisión, entonces resulta vital contar a los migrantes, conocer sus motivaciones para migrar, sus recursos económicos, habilidades laborales, características culturales, su potencial "peligrosidad", en fin: aprehender sus completas existencias para decidir si son aptos y merecedores de formar parte de la comunidad nacional. En este sentido, el Estado continúa su función normalizadora, la cual ha ocupado históricamente en relación a los migrantes, aunque algunos autores señalan que la clásica perspectiva de control es desplazada por una que focaliza en la gestión. Sea una u otra la perspectiva que prevalezca, el migrante emerge en ambas como un asunto a resolver, sobre el que es preciso diseñar una solución. Tal vez por ello, la cuestión de la "legalización" de los extranjeros (además de ser un elemento central para acceder a determinados derechos) ha estado y sigue estando presente a lo largo de la existencia de la Nación Argentina y los últimos años tampoco han sido una excepción. La cuestión es si dicha función estatal obtura otras medidas que pudieran retomarse en vinculación con los derechos de los migrantes así como si dicho rol obsta los avances a nivel de reconocimiento efectivo de los derechos de los extranje$\operatorname{ros}^{19}$.

En conclusión, si bien es preciso reconocer que en la nueva legislación sobre migraciones se privilegia, en mayor medida que en épocas pasadas, una perspectiva de Derechos Humanos, también se ha podido visibilizar que, en las representaciones de los miembros del sistema judicial, la universalidad de reconocimiento de la igualdad entre nativos y extranjeros tiene sus límites. Cabe preguntarse entonces acerca no ya de lo que la ley dice, sino sobre lo que cotidiana y rutinariamente se (re)produce en las prácticas judiciales. En suma, en estas páginas tratamos de preguntarnos acerca de la efectividad de los derechos y de la definición de garantías, entendidas como "la disminución de los obstáculos que de orden económico, cultural o social pudieran limitar de hecho la consecución de derechos..." (Ferrajoli, 1999:110). Podemos afirmar que, cuando esta cuestión no es visibilizada, la diversidad se transfigura en desigualdad. En este caso, lo diverso en relación a la pertenencia a una Nación, distinta a la que se habita, erige una frontera. A nivel representacional parecería que la ciudadanía, definida por la "naturalidad" del lazo del nativo con su nación, continúa prevaleciendo. La ciudadanía se convierte en ese pase al reconocimiento, parafraseando a Arendt (1982), en ese "derecho que habilita a tener derechos" y del que sólo disfrutaría una parte de la humanidad. 
Por último, resulta importante señalar, desde una perspectiva macro de la cuestión, que mientras las migraciones continúen siendo pensadas a nivel internacional como un "problema", consecuentemente las posibles "soluciones" entrarán en contradicción con la retórica y legislaciones basadas en los principios de universalidad de los Derechos Humanos. Lamentablemente, los casos de xenofobia y discursos que exacerban el rechazo a las personas que migran parecieran ser la regla mundial. Los sentimientos de inseguridad institucional, económica y social, que nada tienen que ver con la llegada de los migrantes, sino en todo caso que son efecto de desequilibrios estructurales a escala internacional, son explotados por los gobiernos con el fin de contar con "chivos expiatorios" a los problemas que no pueden/quieren solucionar. En sus extremos, la angustia producida por esta sensación de inseguridad lleva a una interpelación por la "vuelta a los orígenes" de la comunidad imaginaria nacional y, en la praxis, a tendencias de rechazo de lo "otro", que se presenta como amenaza de un "nosotros" vulnerado, y a discursos que hacen alusión a la necesidad de "cerrar las fronteras" y endurecer las políticas migratorias. Así, la relación con los migrantes se torna conflictual. Es en este escenario de crisis que representaciones sociales (como las analizadas en el presente artículo) aletargadas reviven con mayor virulencia. En suma, la cuestión de los derechos humanos de los migrantes nunca debe darse por hecha, sino que supone marchas y contramarchas, es decir, contar con una ley mucho más progresiva que la anterior no asegura que el camino hacia el reconocimiento de los derechos de los migrantes esté saldado, nada asegura que no existan graves retrocesos en dicha materia.

(Recebido para publicação em abril de 2015)

(Reapresentado em novembro de 2016)

(Aprovado para publicação em dezembro de 2016) 


\section{NOTAS}

1. Proyecto UBACyT (Programación Científica 2011-2014) con sede en el Instituto de Investigaciones Gino Germani, Universidad de Buenos Aires.

2. Sobre reflexiones metodológicas al respecto véase Gonzalez y Plotnik (2012).

3. Ley Videla de Inmigración no 23.439, vigente desde 1981 hasta 2003. Disponible en: http://www.mseg.gba.gov.ar/investigaciones/legisla/22439/L22439.htm.

4. Dado que excede a los objetivos del presente artículo un análisis sobre la legislación solo se hará referencia a los artículos que se vinculan con el tema aquí abordado.

5. Ley 25.871, disponible en http://infoleg.mecon.gov.ar/infolegInternet/verNorma.do?id=92016.

6. Entre ellos se encuentran: la Declaración Universal de los DDHH, el Pacto Internacional de los Derechos Económicos, Sociales y Culturales, el Protocolo Facultativo del Pacto Internacional de los Derechos Civiles y Políticos, el Pacto Internacional de los Derechos Civiles y Políticos, el Pacto de San José de Costa Rica, entre otros.

7. Inclusive esa igualdad formal se ve limitada por la asociación de la ciudadanía como pasaporte para el acceso a derechos. Es así que, algunos autores, plantean la necesidad de ampliar "...la mirada para comprender que la desigualdad no solo deviene de una distribución injusta de bienes económicos y sociales sino también del reconocimiento" (Clérico y Aldao, 2011:157). Y, por ende, es preciso dar cuenta de una desigualdad que responde a una desigualdad sistémica estructural que, por tanto, no puede ser resuelta a partir de una respuesta individual (de la que además los propios sujetos excluidos son responsables y deben escaparse), sino que requiere medidas positivas que se traduzcan en una igualdad efectiva de oportunidades para el ejercicio de derechos. Con ese propósito, proponen ampliar la fórmula de igualdad como principio de no-dominación o no-sometimiento (Clérico y Aldao, 2011). Ahora bien, ello implicaría en el caso de los migrantes, poner en evidencia que forman parte de un grupo históricamente excluido y que además esa exclusión responde no a una desigualdad natural sino que es efecto de un modo intra-estatal/nacional de concebir a la ciudadanía y el acceso a derechos.

8. De todos modos, en cada uno de estos tipos de opiniones se encuentra presente la idea de la necesidad de una política migratoria más firme y restrictiva que evite la llegada de migrantes nuevos. Sobre este punto se profundizará en el apartado "Política Migratoria Anhelada".

9. El estudio realizado por Oteiza, Novick, y Aruj es (1996) un ejemplo de ello.

10. En Argentina son conocidos los discursos oficiales durante la presidencia de Menem, de funcionarios que sostenían que los niveles de desocupación se debían a la llegada de inmigrantes de países limítrofes, como así también las campañas con afiches de sindicatos que publicitaban la misma idea.

11. Para ser más precisos, el reconocimiento refería a las personas varones.

12. El tipo de aclaraciones tales como: "no es por discriminar", "puede sonar un poco discriminatorio", "no es por estereotipar" aparece en varias de las entrevistas. En sus investigaciones sobre historias e imaginarios prejuiciosos Van Dijk (1997:187) concluía que "mientras que las personas con prejuicios tenderán a afirmar repetidamente que por supuesto no son racistas, las personas antirracistas no tendrán necesidad de presentarse bajo esta faz positiva. Sus propias historias y argumentos muestran su 
posición". Asimismo, a esta cuestión de los obstáculos que implica estudiar este tipo de fenómenos es a lo que se hizo referencia en el apartado metodológico como "el sesgo de deseabilidad social" (Cea D'Ancona, 2002; 2005).

13. Aquí se retoma la definición de forastero de Schütz (1964), siendo el mismo, aquel sujeto que posee pautas culturales diferentes al de la sociedad receptora. Entendiendo por pauta cultural todos los usos y costumbres, leyes, hábitos, etiquetas y modas.

14. Esta idea de Bauman (1998) implica que el migrante pone en cuestión la extemporalidad que los nativos atribuyen a la organización estatal nacional en la que viven y a partir de la cual se constituyen "sus mundos de la vida".

15. Uno de esos modos de pensar a subvertir es el de la lógica excluyente de ciudadanía y acceso a derechos.

16. En una entrevista realizada a un miembro de la Clínica Jurídica de una ONG argentina que trabaja en defensa de derechos de diversos grupos, entre ellos migrantes, es así explicada la diferencia entre la ley anterior y la actual: "La jurisprudencia tradicional (...) confirmaba que el Poder Ejecutivo, en el marco de la vieja ley, podía detener y expulsar y ¿qué quiere decir esto? Que la autoridad migratoria puede decidir eso sin necesidad de discutir con un juez ni discutir con la propia víctima, ni con el propio extranjero acerca de la necesidad de quedarse o no. Entonces eso lo que impedía eran discusiones jurídicas sobre el tema, entonces lo único que podías hacer era un habeas corpus, que en general se resolvía en contra del extranjero y cuando vos planteabas la apelación y luego de la apelación, la Corte, al extranjero ya lo habían expulsado" [Abogado, Área Litigio y Defensa Legal, Centro de Estudios Legales y Sociales (CELS)]

17. Artículo 61, Ley 25.871.

18. Situación paradojal, ya que es en los últimos años donde se tomaron decisiones (en los que participaron los Poderes Ejecutivo y Legislativo nacionales) en materia migratoria que subsanaron, al menos a nivel normativo, una serie de violaciones a derechos humanos que incluso contrariaban acuerdos y tratados internacionales que Argentina había firmado así como incorporado a su Constitución Nacional en la reforma de 1994. Dos de esas medidas fueron, por ejemplo, el Programa "Patria Grande", que regularizó la situación de un importante número de extranjeros que se encontraban en situación irregular y, en segundo lugar, la derogación de la "Ley Videla" y su reemplazo por la Ley no 25.871 .

19. Mencionar la cuestión de la constante y nunca abandonada función de control de las migraciones por parte del Estado tiene el fin específico de recordar que, dicho rol, excede y traspasa a las administraciones gubernamentales de turno. Todas las administraciones tendrán en cuenta, en mayor o menor medida, pendulando entre el polo de defensa de los derechos humanos y el del control, este rol enfocado en la regularización o legalización de las migraciones. Así, por ejemplo, al momento de escritura de estas páginas comienzan a aparecer manifestaciones desde instancias gubernamentales y legislativas que promueven la necesidad de endurecer la política de ingresos de extranjeros así como la creación de un centro de detención de migrantes. Esta situación reafirma, una vez más la importancia de conocer cuáles son las representaciones sociales que se construyen acerca de los migrantes en las sociedades receptoras, ya que ello nos dará un indicio acerca de cuán exitosos, en cuanto su arraigo y apropiación por "el común de las personas", pueden ser estos discursos excluyentes. 


\section{Anahí González}

\section{BIBLIOGRAFÍA}

ABRAMOVICH, Víctor; COURTIS, Christian. (2006), El Umbral de la Ciudadanía. El Significado de los Derechos Sociales en el Estado Social Constitucional. Buenos Aires, Ed. del Puerto.

ANDERSON, Benedict. (1993), Comunidades Imaginarias: Reflexiones sobre el Origen y la Difusión del Nacionalismo. México, Fondo de Cultura Económica.

ANGENOT, Marc. (2010), El Discurso Social. Los Límites de lo Pensable y lo Decible. Buenos Aires, Siglo XXI.

ARENDT, Hannah. (1998), Los Orígenes del Totalitarismo. Buenos Aires, Taurus.

ASA, Pablo; CERIANI CERNADAS, Pablo. (2010), “Migrantes, Derechos Sociales y Políticas Públicas en América Latina y el Caribe: La Universalidad en Juego", en VV.AA., Derechos Sociales: Justicia, Política y Economía en América Latina. Colombia, Siglo del Hombre.

BACZKO, Bronislaw. (1999), Los Imaginarios Sociales: Memorias y Esperanzas Colectivas. Buenos Aires, Nueva Visión.

BAILY, Samuel I. (1988), “Cadenas Migratorias de Italianos a la Argentina: Algunos Comentarios. Estudios Migratorios Latinoamericanos.

BALIBAR, Etienne. (1988), “La forma Nación: historia e ideología. En E. Balibar, \& I. Wallerstein, Raza, Nación y Clase (págs. 135-167). Madrid: IEPALA.

BALIBAR, Etienne. (2005), Violencias, Identidades y Civilidad. Barcelona, Gedisa.

BAUMAN, Zygmunt. (1998), La Globalización. Consecuencias Humanas. México, Fondo de Cultura Económica.

. (2005), Comunidad: En Busca de Seguridad en un Mundo Hostil. Buenos Aires, Siglo XXI Editores.

BERGER, Peter; LUCKMANN, Thomas. (1986), La Construcción Social de la Realidad. Buenos Aires, Amorrotu.

BLANCO, Cristina. (2006), Migraciones: Nuevas Modalidades en un Mundo en Movimiento. Barcelona, Anthropos.

CEAD’ANCONA, Maria Ángeles. (2002), “La Medición de las Actitudes ante la Inmigración: Evaluación de los Indicadores Tradicionales de 'Racismo'". Reis: Revista Española de Investigaciones Sociológicas, no 99, pp. 87-111.

. (2005), "La Exteriorización de la Xenofobia”. Reis: Revista Española de Investigaciones Sociológicas, no 112, pp. 197-230.

CELS. (2008). La lucha por el derecho. Litigio estratégico y Derechos Humanos. Buenos Aires, Siglo XXI Ed.

CERIANI CERNADAS, Pablo. (Noviembre de 2012), Apuntes críticos sobre los derechos humanos, migraciones y libre circulación de personas en el MERCOSUR. Derechos Humanos. Reflexiones desde el sur, 10.

CERIANI CERNADAS, Pablo; FAVA, Ricardo. (2009), Políticas Migratorias y Derechos Humanos. Buenos Aires, Ediciones de la UNLa. 
CERIANI CERNADAS, Pablo; MORALES, D.; RICART, L. (2007), “Los Derechos de los Migrantes en la Jurisprudencia Argentina", en V. Abramovich; A. Bovino; C. Courtis (comp.), La Aplicación de los Tratados sobre los Derechos Humanos en el Ámbito Local. La Experiencia de una Década. Buenos Aires, Ed. del Puerto, pp. 813-882.

CLÉRICO, Laura; ALDAO, Martín. (2011), “La Igualdad como Redistribución y como Reconocimiento: Derechos de los Pueblos Indígenas y Corte Interamericana de DD.HH". Estudios Constitucionales, vol. 9, no 1, pp. 157-198.

CLÉRICO, Laura; RONCONI, Liliana; ALDAO, Martín. (2013), “Hacia la Reconstrucción de las Tendencias Jurisprudenciales en América Latina y el Caribe en Materia de Igualdad: Sobre la No-discriminación, la No-dominación y la Redistribución y el Reconocimiento". Revista Direito GV, vol. 9, no 1, pp. 115-170.

COHEN, Néstor. (2009), “No es sólo Cuestión de Migrantes: Migraciones Externas y Exclusión Social", en S. Goinheix (ed.), Conflictos y Expresiones de la Desigualdad y la Exclusión en América Latina. Buenos Aires, El Aleph.

. (2012), "Profetizando al Diferente". Revista Controversias y Concurrencias Latinoamericanas, no 6, pp. 187-203.

; MERA, Carolina. (2005), Relaciones Interculturales: Experiencias y Representación Social de los Migrantes. Buenos Aires, Antropofagia.

DE LUCAS, Javier. (2004), “La Inmigración como Res Política”. Cuadernos Electrónicos de Filosofía del Derecho, no 10, pp. 1-44.

DOMENECH, Eduardo. (2011), “Crónica de una 'Amenaza' Anunciada. Inmigración e 'Ilegalidad': Visiones de Estado en la Argentina Contemporánea”, en L. FeldmanBianco; C. Rivera Sánchez; M. Villa Martínez (comp.), La Construcción Social del Sujeto Migrante en América Latina: Prácticas, Representaciones y Categorías. Quito, CLACSO, pp. 31-77.

ELIAS, Norbert. (2006), Sociología Fundamental. España, Gedisa.

FERRAJOLI, Luigi. (1999), Derechos y Garantías: La Ley del más Débil. Madrid, Ed. Trotta.

GERMANI, Gino. (1964), Assimilation of Inmigrants in Urban Areas: Methodological Notes. Buenos Aires, Instituto Torcuato Di Tella/Centro de Sociología Comparada.

. (2010), La Sociedad en Cuestión: Antología Comentada. Buenos Aires, UBA, FCS IIGG, CLACSO.

HOBSBAWM, Eric. (2004), Naciones y Nacionalismo desde 1780. Barcelona, Crítica.

JODELET, Denise. (1986), "La Representación Social: Fenómenos, Concepto y Teoría", en S. Moscovici, Psicología Social. Barcelona, Paidós, pp. 469-494.

MÁRMORA, Lelio. (2004), “Las Leyes de Migraciones como Contexto Normativo. (De la Ley Videla a la Ley de Migraciones 25.871)", en R. Giustiniani (ed.), Migración: Un Derecho Humano. Buenos Aires, Prometeo, pp. 59-66.

MEZZADRA, Sandro. (2012), “Capitalismo, Migraciones y Luchas Sociales. La Mirada de la Autonomía". Nueva Sociedad, no 237, pp. 159-178.

MORALES, Diego. (2012), “Derechos Humanos de los Migrantes en la Argentina. Apuntes sobre nuevas Perspectivas Jurisprudenciales". Revista de Derecho Público, vol. 1, no 2.

DADOS - Revista de Ciências Sociais, Rio de Janeiro, vol. 60, nº 1, 2017 


\section{Anahí González}

MOSCOVICI, Serge. (1979), El Psicoanálisis, su Imagen y su Público. Buenos Aires, Huemul.

NOVICK, Susana. (2008), Las Migraciones en América Latina: Políticas, Culturas y Estrategias. Buenos Aires, CLACSO.

OTEIZA, Enrique; NOVICK, Susana. (2000), Inmigración y Derechos Humanos [Política y Discurso en el Tramo Final del Menemismo]. Buenos Aires, UBA. Facultad de Ciencias Sociales, Instituto Gino Germani.

OTEIZA, Enrique; NOVICK, Susana; ARUJ, Roberto. (1996), “Política Migratoria, Inmigración Real y Derechos Humanos en Argentina". Documento de Trabajo n5, Instituto de Investigaciones Gino Germani, Facultad de Ciencias Sociales, UBA.

PACECCA, Maria Ines. (2006), “Migraciones e Interculturalidad”, en A. Jure (ed.), Diversidad Cultural e Interculturalidad. Buenos Aires, Prometeo, pp. 277-280.

(2001), Migrantes de Ultramar, Migrantes Limítrofes. Políticas Migratorias y Procesos Clasificatorios. Argentina, 1945-1970. CLACSO.

PEDONE, Claudia. (2010), “Cadenas y Redes, Migratorias: Propuesta Metodológica para el Análisis Diacrónico Temporal de los Procesos Migratorios". Empiria: Revista de Metodología de Ciencias Sociales, no 19, pp. 101-132.

PEREZ AGOTE, Alfonso. (1993), “Las Paradojas de la Nación”. REIS, no 61, pp.7-21.

PLOTINIK, Gabriela; GONZÁLEZ, Anahí. (2012), El Sesgo de “Deseabilidad Social” en el Abordaje del Fenómeno de la Discriminación en las Relaciones Interculturales: Algunas Reflexiones sobre las Guías de Pauta como "Teorías en Acto". Trabalho apresentado nas Jornadas de Sociología de la UNLP: "Argentina en el Escenario Latinoamericano Actual: Debates desde las Ciencias Sociales", 5 al 7 de diciembre, UNLP, Ciudad de La Plata, Argentina.

SANTAMARÍA, Enrique. (2010), La Incógnita del Extraño. Barcelona, Anthropos.

SASSEN, Saskia. (2007), Una Sociología de la Globalización. Buenos Aires, Kats Editores. (2013), Inmigrantes y Ciudadanos. Madrid, Siglo XXI.

SUAREZ NAVAS, Liliana. (2008), “La Perspectiva Transnacional en los Estudios Migratorios: Génesis, Derroteros y Surcos Metodológicos", en J. García Roca; J. Lacomba Vázquez (coords.), La Inmigración en la Sociedad Española: Una Radiografía Multidisciplinar. Barcelona, Ediciones Bellaterra, pp.771-796.

TERRÉN, Eduardo. (2003), “La Ironía de la Solidaridad: Cultura, Sociedad Civil y Discursos sobre el Conflicto Racial de El Ejido”. REIS, no 102, 125-146.

VAN DIJK, Teun A. (1997), "Historias y Racismo", en D. Mumby (ed.), Narrativa y Control Social. Perspectivas Críticas. (págs. 163-189). Buenos Aires: Amorrortu.

ZAMORA, José A. (2005), "Políticas de Inmigración, Ciudadanía y Estado de Excepción". ARBOR. Ciencia, Pensamiento y Cultura (CLXXXI), pp. 53-66. 


\section{RESUMO}

Limites da Universalidade dos Direitos Humanos: Representações Sociais e o Sistema Judicial sobre os Migrantes Internacionais como Titulares de Direitos

O presente artigo aborda as representações sociais presentes no sistema judiciário da Área Metropolitana de Buenos Aires (AMBA), no que diz respeito aos direitos humanos dos migrantes internacionais vindos à Argentina desde meados do século XX até a atualidade. A partir de uma pesquisa de caráter qualitativo, que realizou cinquenta entrevistas minuciosas junto a membros do sistema judiciário da AMBA, se evidenciam discursos excludentes, distantes de uma perspectiva universalista e respeitosa aos direitos dos imigrantes. Ao examinar os resultados encontrados, são discutidas três dimensões de análises: a política migratória almejada, a competição entre nativos e migrantes no que tange ao acesso a direitos econômicos e sociais e, finalmente, a concepção de cidadania restringida.

Palavras-chave: direitos humanos; universalidade; representações sociais; migrações; sistema judiciário

\section{ABSTRACT \\ Limits to the Universality of the Concept of Human Rights: Social Representations in the Judicial System of International Migrants as Rights Holders}

The following article discusses the social representations present in the judicial system in the Metropolitan Area of Buenos Aires (MABA) in terms of the human rights of the international migrants to have arrived in Argentina as of the mid twentieth century. By means of a qualitative study encompassing fifty in-depth interviews held with members of the MABA judicial system, exclusionary discourse emerged running against the universalist perspective that respects migrants' rights. Upon further study of the results gathered, three lines of analysis are discussed: desired migration policies, competition between locals and migrants in accessing economic and social rights, and, finally, the concept of restricted citizenship.

Key words: human rights; universality; social representations; migration; judicial system 


\section{RÉSUMÉ}

Les Limites de l'Universalité des Droits de l'Homme: Représentations Sociales de l'Appareil Judiciaire sur les Migrants Internationaux en tant que Titulaires de Droits

Le présent article aborde les représentations sociales présentes au sein de l'appareil judiciaire de la Zone métropolitaine de Buenos Aires (AMBA) sur la question des droits humains des migrants internationaux arrivés en Argentine depuis le mitan du XX⿳亠丷⿵冂⿱十口犬e siècle. Sur la base d'une recherche qualitative où cinquante entretiens en profondeur ont été menés à bien avec des membres de l'appareil judiciaire de l'AMBA, nous avons pu mettre en évidence des discours excluants contraires à la perspective universaliste et au respect des droits des migrants. L'étude des résultats obtenus a mis en perspective trois dimensions analytiques : la politique migratoire désirée, la concurrence entre natifs et migrants pour l'accès aux droits économiques et sociaux, et, finalement, une conception restreinte de la citoyenneté.

Mots-clés: droits de l'Homme; universalité; représentations sociales; migrations; système judiciaire

\section{RESUMEN}

Limites a la Universalidad de los Derechos Humanos: Representaciones Sociales en el Sistema Judicial sobre los Migrantes Internacionales como Titulares de Derechos

El presente artículo aborda las representaciones sociales presentes en el sistema judicial del Área Metropolitana de Buenos Aires (AMBA) acerca de los derechos humanos de los migrantes internacionales llegados a la Argentina desde la mitad del siglo XX a la actualidad. A partir de una investigación de carácter cualitativo, que llevó a cabo cincuenta entrevistas en profundidad a miembros del sistema judicial del AMBA, se evidencian discursos excluyentes que se alejan de una perspectiva universalista y respetuosa de los derechos de los migrantes. Al analizar los resultados encontrados, se discuten tres dimensiones de análisis: la política migratoria anhelada, la competencia entre nativos y migrantes en el acceso a derechos económicos y sociales y, finalmente, la concepción de ciudadanía restringida.

Palabras clave: derechos humanos; universalidad; representaciones sociales; migraciones; sistema judicial 